\title{
Jogo, Curiosidade e Ad-Miração: Indícios de aproximação entre a pedagogia da autonomia freireana e a pegadogia do teatro
}

\author{
Henrique Bezerra de Souza \\ Universidade do Estado de Santa Catarina - UDESC, Florianópolis/SC,Brasil \\ E-mail: henriquebezerrads@gmail.com
}

\section{Resumo}

O presente artigo investiga a aproximação entre a noção de autonomia - tal como cunhada por Paulo Freire (2004a) - e a prática do jogo em processos de ensino-aprendizagem em teatro. Para tanto, tece uma breve apresentação das ideias do educador pernambucano a respeito do processo de construção de conhecimento, para, em seguida, relacionar tais reflexões a elementos presentes na prática do jogo. $\mathrm{Na}$ tentativa de encontrar os primeiros indícios dessa aproximação, toma como ponto de partida as características que Johan Huizinga (2010) atrela ao ato de jogar e, em seguida, analisa os jogos teatrais de Viola Spolin (2018), buscando neles similaridades ao pensamento freireano. Nesse trajeto, se depara com desdobramentos que trespassam a metodologia realizada em sala de aula, revelando a importância da postura do sujeito docente no processo pedagógico.

Palavras-chave

Autonomia. Jogo. Ensino-Aprendizagem.

Paulo Freire. Pedagogia do Teatro.
Abstract

This article investigates the approximation between the notion of autonomy - as defended by Paulo Freire - and the practice of the play in teaching-learning processes in theater. In order to do that, it makes a brief presentation of Paulo Freire's studies regarding the process of building knowledge, relating these reflections to elements present in the practice of the play. In an attempt to find the first signs of this approximation, it takes as a starting point the characteristics that Johan Huizinga assigns to the act of playing and then analyzes Viola Spolin's theater games, looking for similarities to Freire's thought. In this contact, discovers developments that cross the methodology used out in the classroom, revealing the importance of the teacher's posture in the pedagogical process.

Keywords

Autonomy. Play. Teaching-learning. Paulo Freire. Theater Pedagogy. 
A noção de "jogo" tem presença constante nos estudos vinculados à pedagogia do teatro. Seja na comunidade ou na escola, dificilmente se encontra uma proposta de ensino-aprendizagem em teatro que não lide com ele em alguma das etapas do processo. Seu potencial pedagógico já foi investigado em diversas proposições que o tem como um dos elementos constituintes, tais como os Jogos Teatrais, Jogos Dramáticos, Teatro do Oprimido, Drama ${ }^{1}$, entre outros.

Com efeito, sua prática carrega a possibilidade de compreensão do aprendizado em teatro por meio da vivência, ou seja, da prática, observação e avaliação do que foi realizado. Com isso, a apropriação dos elementos da linguagem cênica ocorre como uma construção de conhecimento, fugindo assim de uma possível concepção de ensino que se restrinja a uma lógica replicante, de repasse de informações e modos de fazer. Nessa esteira, proposições de ensino-aprendizagem em teatro pautadas pela lógica do jogo podem trazer indícios para o fomento da autonomia dos sujeitos. Termo este entendido aqui sob a ótica defendida por Paulo Freire (2004a).

Diante destas observações, este artigo é dedicado a realizar uma aproximação teórica das reflexões do educador pernambucano à pedagogia do teatro, buscando assim desvelar como seus estudos podem se fazer presentes em proposições de ensino-aprendizagem pautadas pelo jogo, dando enfoque aos jogos teatrais de Viola Spolin (2018).

\section{Considerações sobre o ato de ensinar e aprender}

Para realizar o intento deste texto, nos afastamos brevemente do escopo teatral para nos debruçar sobre os estudos de Paulo Freire. O autor traçou não só um método de alfabetização, mas uma reflexão complexa sobre o ato de ensinar e aprender, cravando com isto raízes profundas na filosofia da educação.

1 Para mais informações a respeito destas proposições, consultar respectivamente SPOLIN (2018), RYNGAERT (2009), BOAL (1980) e CABRAL (2006).
Em sua visão, há um problema quando o ensino é concebido como uma hierarquia de saberes de um ser sobre o outro, na qual o primeiro deposita as informações e, consequentemente, suas visões de mundo sobre o segundo.

Caso seja tratado dessa forma, o processo pedagógico se torna mera repetição de informes e anula sua potência processual, transformadora, contribuindo assim para a ratificação de formas de ser e saber hegemônicas. Essa postura aniquila o potencial humano do aprendiz que passa a se ver não como sujeito capaz de refletir e questionar o apreendido, mas como coisa ${ }^{2}$ (FREI$\mathrm{RE}, 2004 \mathrm{~b})$ que simplesmente arquiva conteúdos.

As consequências dessa forma limitante de lidar com o processo pedagógico podem fazer com que o sujeito se veja como "incapaz" e relegue toda a responsabilidade do saber a um outro ser. Concretiza-se assim, uma espécie de heteronomia (FREIRE, 2004a), posto que o indivíduo crê que não é autônomo o suficiente para questionar o apreendido e tecer considerações a respeito do objeto de conhecimento. Nessa dinâmica, seu papel se deteria a aceitar o conjunto de informes que lhe são passados. Esse processo dá forma ao que Freire chama de concepção bancária da educação (FREIRE, 2004b), um modo de ver a prática educativa por meio de depósitos nos seres, minando seu potencial transformador ao encará-los como "coisas" (FREIRE, 2004b).

Seguindo suas reflexões, o autor considera que o aprendizado é, na realidade, uma construção, não um repasse. $O$ processo de ensino-aprendizagem deve ser cultivado juntamente com os aprendizes por meio de uma ação coletiva que leva em considera-

2 Na visão de Freire, os seres humanos carregam a possibilidade de agir sobre o mundo refletindo sobre ele, questionando e o transformando. Dessa forma, o potencial de ação transformadora é uma das características que os fazem sujeitos. Tal condição não é partilhada pelos objetos ou coisas que simplesmente existem no mundo, não podendo alterá-lo diretamente sem a ação humana. Portanto, quando algo restringe e retira o potencial questionador e transformador do indivíduo no mundo, Freire alega que $o$ ato limou sua existência de sujeito tornando-o "coisa". Para mais informações ver FREIRE (2004b). 
ção suas visões de mundo e decorrentes críticas, de modo que, neste processo, discentes, que ele chamará de educandos-educadores (FREIRE, 2004b), e docentes, chamados de educadores-educandos, descobrem o próprio aprendizado por meio de uma investigação em grupo sobre o objeto cognoscível.

Nesta acepção, a contradição entre educador e educando é superada ao clamar que todos são sujeitos do ato pedagógico. Ao refletirem juntos sobre o objeto de estudo, aprendem e ensinam mutuamente na partilha de reflexões, construindo assim o conhecimento. Apesar de aparentemente simples, essa visão encoraja o sujeito discente a não se contentar com uma postura apassivada, mas a tornar-se um dos produtores do próprio saber. Ele, em conjunto com os outros envolvidos no processo de ensino-aprendizagem, observa, critica e reflete sobre o objeto investigado, tecendo também suas próprias considerações. Tem-se, então, uma visão de saber que enfatiza o processo, que não se limita a repetir o já sabido, que pode desvelar outras camadas do tema desconhecido quando sua objetividade é confrontada com a subjetividade de seus participantes.

Para que esse processo não se perca em "tergiversações e achismos" sobre um tema, há que se estimular uma investigação além da superfície. Nessa perspectiva, reconhecer os saberes do educando-educador como componentes do processo de ensino-aprendizagem pode fomentar um potencial processual na construção do conhecimento, mas isto não significa se ater as suas impressões iniciais, crenças e dogmas. Pelo contrário, deve fazê-lo questionar estas concepções no confronto com as indagações que o próprio objeto de estudo lança e com as provocações do educador-educando. Em síntese, reconhecer os saberes, mas não se manter no nível superficial, estimular a investigação e promover o que Freire chama de curiosidade epistemológica (FREIRE, 2004a).

O termo "curiosidade" é muito presente nos estudos do autor e aparece em sua obra antes mesmo dele cunhar a noção acima apontada. Para Freire, a curiosidade é a pedra fundamental do aprendizado. É por meio da capacidade de obser- var o mundo e indagá-lo que os indivíduos se tornam capazes de agir sobre a realidade, aprender e, com isso, promover mudanças. Em sua concepção, essa mesma curiosidade se divide em dois níveis: a ingênua (também chamada de espontânea) e a crítica (também chamada de epistemológica).

A curiosidade ingênua (FREIRE, 2004a) se dá no nível superficial, frente às questões que o objeto de estudo pode lançar, mas, conforme o sujeito aprofunda a investigação em busca de possíveis respostas, passa a consultar outras fontes, a criar métodos, e a desenvolver certo rigor nesta pesquisa, ela se transforma. Este processo de busca faz com que a curiosidade ingênua vá se tornando epistemológica, crítica. No livro Política e Educação, Freire (2001) traz uma das primeiras definições do termo em que afirma:

A curiosidade de que falo não é, obviamente, a curiosidade "desarmada" com que olho as nuvens que se movem rápidas, alongando-se umas nas outras, no fundo azul do céu. É a curiosidade metódica, exigente, que, tomando distância do seu objeto, dele se aproxima para conhecê-lo e dele falar prudentemente. É a curiosidade epistemológica. (FREIRE, 2001, p. 55).

Em Pedagogia da Autonomia ele retoma o conceito, abordando como a curiosidade ingênua pode se tornar epistemológica. Nas palavras do autor:

Que "tratamento" [o sujeito] deu à curiosidade, se facilmente foi superada ou se, pelo contrário, conduziu a outras curiosidades. Se no processo curioso consultou fontes, dicionários, computadores, livros, se fez perguntas a outros. Se a curiosidade enquanto desafio provocou algum conhecimento provisório de algo, ou não. [...] O exercício da curiosidade a faz mais criticamente curiosa, mais metodicamente "perseguidora" do seu objeto. Quanto mais a curiosidade espontânea se intensifica, mas, sobretudo, se "rigoriza", tanto mais epistemológica ela vai se tornando. [...] Quanto mais faço estas operações com maior rigor metódico tanto mais me aproximo da maior exatidão dos achados de minha curiosidade. Um dos saberes fundamentais à minha prática educativo-crítica é o que me adverte da necessária promoção 
da curiosidade espontânea para a curiosidade epistemológica. (FREIRE, 2004a, p. 87).

Nessa citação, o autor evidencia que um dos principais papeis da prática educativo-crítica é estimular a transição da curiosidade espontânea para a epistemológica. Enquanto a concepção bancária da educação distribui certezas, respostas prontas e informações findadas que o indivíduo deve memorizar, a prática educativo-crítica fomenta a curiosidade, encorajando o sujeito a pesquisar sobre aquilo que o move, construindo assim suas considerações de maneira crítica. Reitero que tais ponderações não se atêm a opiniões, dogmas ou crenças, mas, são construídas por meio de questionamentos, investigações rigorosas sobre o objeto de estudo para que então ele possa ser relido sob a ótica do sujeito pesquisador.

Tal ato concentra em si um processo que Freire chama de ad-mirar (FREIRE, 2018) o objeto de estudo. Ad-mirar, para o autor, é observar diretamente o objeto cognoscível, "tomar distância" dele para questionar as possíveis relações já estabelecidas pelo uso cotidiano ou hegemônico. Em síntese, é tornar algo alvo do olhar e estranhar o que aparentemente já é conhecido para que se possa desenvolver uma postura curiosa e investigativa.

Ao ad-mirar algo, além de re-conhecer o objeto de investigação, se ad-mira também o conhecimento prévio que se tem sobre ele, percebendo assim condicionamentos e limitações primevas de sua compreensão. Em síntese:

Ad-mirar implica pôr-se em face do "não-eu", curiosamente, para compreendê-lo. Por isso, não há ato de conhecimento sem admiração do objeto a ser conhecido. Mas se o ato de conhecer é um processo - não há conhecimento acabado - ao buscar conhecer ad-miramos não apenas o objeto, mas também a nossa ad-miração anterior do mesmo objeto. (FREIRE, 2018, p. 84, 85).

A lógica bancária, diferentemente, fomenta a heteronomia pois os educandos não são estimulados a lançar um olhar curioso, a ad-mirar e tecer suas considerações sobre o objeto de estudo. Quando muito, replicam os sinais de uma ad-miração introjetada, tecida pelo docente, sem elaborar uma reflexão.

Já na prática educativo-crítica, o estímulo à curiosidade e ad-miração de um objeto de estudo coloca o sujeito como um dos responsáveis pela construção dos próprios saberes, atribuindo-Ihe a necessidade de interpretar, criticar, refletir sobre o que investiga e sobre as decisões desse ato, bem como vivenciar as consequências deste processo de construção do saber.

Em outras palavras, implica num trabalho ativo do educando-educador, obrigando-o a preencher o vazio deixado pelos informes do educador bancário com as reflexões que tece no confronto com o objeto de estudo. Logo, quando o aprendiz adquire espaço para tomar decisões e conduzir - em certa medida o próprio processo de ensino-aprendizagem, a heteronomia dá lugar à autonomia. Como defende Freire:

\begin{abstract}
Ninguém é autônomo primeiro para depois decidir. A autonomia vai se constituindo na experiência de várias, inúmeras decisões, que vão sendo tomadas. [...] Ninguém é sujeito da autonomia de ninguém. [...] A autonomia, enquanto amadurecimento do ser para si, é processo, é vir a ser. Não ocorre em data marcada. É nesse sentido que uma pedagogia da autonomia tem de estar centrada em experiências estimuladoras de decisão e da responsabilidade, vale dizer, em experiências respeitosas da liberdade. (FREIRE, 2004a, p. 107)
\end{abstract}

O que deriva disto é que, assumindo a função docente como educador-educando, a tarefa não se concentra em um repasse de conteúdos e informações, mas em fazer com que o estudante se veja como sujeito capaz de saber. Desafiá-lo a tal ponto que se perceba como um indivíduo apto a construir conhecimento. Na pedagogia do teatro, campo de estudo deste artigo, isto significa considerar os saberes prévios do educando-educador, colocar sua subjetividade em choque com a objetividade do ponto de estudo, de modo que estimule o sujeito a se entender como pessoa que pode criar, observar e refletir sobre a linguagem teatral. 


\section{Considerações sobre o jogo}

Tendo os apontamentos acima em vista, cabe considerar as possíveis aproximações dessas ideias com os estudos acerca do jogo. Para tanto, as observações que o historiador holandês Johan Huizinga realizou sobre o termo podem auxiliar neste objetivo.

Em Homo Ludens, Huizinga (2010) aponta a importância do conceito de jogo para compreensão do desenvolvimento humano, discutindo-o principalmente sob uma perspectiva cultural.

Ao compreender o jogo como um elemento da cultura e buscar confluências entre ele e as atividades dos indivíduos, Huizinga passa a listar características para o ato e, assim, fornece, ainda que inicialmente, subsídios que ajudam a definir o que é compreendido como jogar. O autor elenca algumas das características que compõem a ideia de jogo, tais como: atividade regrada, realizada voluntariamente pelos envolvidos, circunscrita em determinados limites de espaço-tempo e autossuficiente, ou seja, não busca produzir algum ganho ou satisfazer uma necessidade imediata (a não ser as da própria execução). Em suas palavras:

\begin{abstract}
O jogo é uma atividade ou ocupação voluntária, exercida dentro de certos e determinados limites de tempo e de espaço, segundo regras livremente consentidas, mas absolutamente obrigatórias, dotado de um fim em si mesmo, acompanhado de um sentimento de tensão e de alegria e de uma consciência de ser diferente da 'vida quotidiana'. (HUIZINGA, 2010, p. 33).
\end{abstract}

Por ocorrer em um espaço-tempo distinto e com regras que diferem da vida cotidiana, o jogo cria uma realidade lúdica sustentada pelo empenho dos jogadores e por sua fidelidade às regras que aceitaram cumprir. Em síntese, estes princípios estabelecem maneiras de agir dentro do jogo - movimentos das peças no tabuleiro, regras para manuseio da bola, campo onde a competição é válida... - e, por sua vez, o destacam do mundo real, criando o que o autor chama de círculo mágico (HUIZINGA, 2010). Assim, o jogo é lançado para uma realidade lúdica na qual essas leis são as responsáveis por dimensionar as ações válidas para resolução dos desafios propostos.
Contudo, cabe destacar que inscrito no tecido do real - visto que é praticado por seres viventes que, de fato, existem, mas ainda assim deslocado, pois não segue necessariamente as regras do mundo cotidiano - é possível inferir que o jogo adquire uma existência dupla ao transformar em realidade lúdica elementos e posturas que, à primeira vista, poderiam ser vistos apenas como mundanos. Nessa coexistência, materialidades, indivíduos e ações podem ser ressignificados de modo que, mesmo que não façam sentido algum no contexto cotidiano, signifiquem algo dentro do jogo.

O círculo mágico atua não como um marco físico, mas virtual, que condiciona o sujeito a enxergar de outro modo, sob o véu lúdico, atividades e símbolos que antes poderiam parecer corriqueiros. Portanto, essa existência dupla delimita um espaço de entrelugar onde coexistem duas realidades instauradas no campo simbólico e no campo visível - a do jogo e a do cotidiano.

Essas realidades sobrepostas implicam em dinâmicas de risco, à medida que as ações do jogo convivem com as ações do cotidiano; uma ação ocorrida em um jogo pode possuir um sentido dentro do círculo mágico que difere dos que poderia adquirir fora do mundo lúdico. Esse deslocamento pode revelar outras formas de relação entre os seres consigo, com os outros e com objetos, pois as regras do jogo que medeiam a relação entre os jogadores podem reconstruir, em alguma medida, formas de comportamentos tidas como corriqueiras. Logo, em jogo, surgem pequenas frestas de ação que propiciam o questionamento de valores, ações ou até mesmo de indivíduos que tentam exercer alguma hegemonia no cotidiano.

Além deste conjunto de regras que delimita o contexto do jogo, ele propõe questões, desafios a serem resolvidos pelo indivíduo ou grupo, centralizando assim a atenção dos jogadores. As soluções vindouras não surgem necessariamente de um encadeamento racional, mas da prática do ato, do confronto do participante com a situação em execução. Essas soluções vêm na forma do que Huizinga chama de rasgos de intuição (HUIZINGA, 2010). 
Ainda que o autor use este termo uma única vez em seu estudo e não se aprofunde em sua discussão, é pertinente refletir sobre o que esta ideia pode evocar. Na prática do jogo, o jogador lida com um problema que não possui uma solução singular, mas formas possíveis de ser abordado. Desta maneira, com base nas experiências que já possui e no que as regras do jogo lhe impõem, cabe ao indivíduo decidir como lidar com a situação. Algumas vezes, a tensão, alegria e engajamento que a prática lúdica evoca nublam a racionalização do ato, o que, por sua vez, pode auxiliar na quebra de padrões estabelecidos e roteiros pré-concebidos. Então, ao ver-se confrontado na problemática do momento presente, o jogador só tem como escolha tomar uma decisão no rápido instante de incerteza; escolha esta que surge como um rasgo de intuição.

Transpor essas observações para a situação pedagógica parece fomentar a autonomia do sujeito na construção do conhecimento. Em jogo o participante não está sendo guiado por alguém que lhe apresenta as fórmulas de como resolver a situação, não há um professor explicador indicando caminhos corretos e determinados. Pode-se até afirmar que isso aconteceria em uma etapa prévia, por meio de treino ou aprendizado técnico que auxiliariam o jogador em sua prática. No entanto, na situação lúdica em si, no momento da execução do jogo, o que se tem é um certo desamparo, o jogador é lançado frente a um problema e tem que resolvê-lo. Para isso, conta apenas com suas experiências e as relações que tece entre elas, as regras e a provocação proposta pela situação lúdica. Logo, no microcosmo do jogo, se encontram indícios de um abandono da heteronomia em favor da autonomia.

Atrelar este pensamento à pedagogia do teatro desvela a potência do jogo como ponto privilegiado para construção de conhecimento. Um processo de ensino-aprendizagem que o tenha como mote pode ser concebido como uma investigação de desafios lúdicos regrados que são solucionados individualmente ou em grupo. Na resolução dessas questões, o participante entra em conta- to, aprende e ressignifica elementos da linguagem teatral à medida que os vivencia, observa e critica.

O jogo funciona, então, como um ponto comum que medeia os estudos dos participantes do processo de ensino-aprendizagem. Com isso, a linguagem teatral não é introjetada nos discentes, mas descoberta por eles e elas. Ainda sobre este ponto, a própria figura docente pode também redescobrir o já sabido ao jogar, analisar e criticar o que for vivenciado junto com seus educandos-educadores.

Cabe ressaltar que tais argumentos não significam abandonar discentes a própria sorte na vivência da linguagem cênica. Fazer isto seria corromper o discurso da autonomia em favor de um espontaneísmo ${ }^{3}$ que pouco contribui para a pedagogia do teatro. Como discutido ao longo deste manuscrito, o processo de ensino-aprendizagem aqui discutido é uma ação coletiva, não prescinde da figura docente, mas também não se centra nela.

Por fim, para aprofundar estas investigações, este texto se volta para uma das principais propostas pedagógicas que toma o jogo como elemento constituinte: os Jogos Teatrais de Viola Spolin (2018).

\section{Jogos teatrais e ecos freireanos}

Uma leitura superficial do trabalho de Spolin pode fazer com que ele seja confundido apenas como uma série de exercícios para serem praticados em sala de aula, entendimento este que está muito aquém de sua proposta.

Os jogos teatrais funcionam como um sistema que explora elementos da linguagem teatral na

\footnotetext{
3 Influenciado pelo escolanovismo e pelas ideias de Jean Jacques Rousseau e John Dewey, a ideia de uma "educação a partir da criança" ganhou força no ensino de arte brasileiro, principalmente na década de 70 . Contudo, uma compreensão equivocada dos estudos dos autores passou a defender o que ficou conhecido como "espontaneísmo" dos alunos. Nesta defesa, pecava por uma generalização do ensino e falta de critérios claros no processo de formação dos estudantes. Ao acreditar em uma forma pura de arte infantil, pregava um jogo livre com foco centrado na ação espontânea sem colocar os participantes em contato com obras, trabalhos e pensamentos acerca da linguagem artística já existente.
} 
forma de atividades lúdicas improvisadas, fazendo com que sua investigação se dê por meio da prática, observação e avaliação dos jogos desenvolvidos. Para tanto, possuem três elementos estruturantes: o foco que funciona como o ponto de concentração da atenção dos jogadores, as instruções que atuam como a intervenção do coordenador para a retomada do foco em casos de dispersão e, por fim, a avaliação, momento que ocorre após a prática do jogo no qual os participantes avaliam sua execução com critérios objetivos, vinculados ao foco.

Um dos pontos-chave dessa proposta está na criação de problemas que são resolvidos na situação de jogo. Nas palavras da autora:

Qualquer jogo digno de ser jogado é alta-
mente social e propõe intrinsecamente um
problema a ser solucionado - um ponto
objetivo com o qual cada indivíduo deve
se envolver [...] Os jogadores tornam-se
ágeis, alerta, prontos e desejosos de novos
lances ao responderem aos diversos acon-
tecimentos acidentais simultaneamente. A
capacidade pessoal para se envolver com
os problemas do jogo e o esforço dispen-
dido para lidar com os múltiplos estímulos
que ele o provoca, determinam a extensão
desse crescimento. [...] A energia liberada
para resolver o problema, sendo restrin-
gida pelas regras do jogo e estabelecida
pela decisão grupal, cria uma explosão
- ou espontaneidade - e, como é comum
nas explosões, tudo é destruído, rearran-
jado, desbloqueado. (SPOLIN, 2018, p. 5).

Este discurso da autora a respeito da explosão, em muito se aproxima do rasgo de intuição e de uma reinvenção de saberes, de uma construção de conhecimento. Ao "destruir e rearranjar" o que quer que seja experimentado, o jogador remonta, sob sua perspectiva, o desenlace da situação lúdica e pode sair dela com uma descoberta pessoal do feito. Seguindo este movimento, é possível encontrar assimilações com as proposições discutidas no início deste texto.

Se um dos fundamentos da autonomia está vinculado à tomada de decisões, na prática do jogo, um campo de experimentação para isso é proposto ao criar desafios dentro de certo espaço de seguran- ça, na zona intermediária do círculo mágico, ou seja, uma realidade lúdica regida por regras que diferem da vida cotidiana, mas que não está completamente apartada dela. Esses desafios engajam o participante a resolvê-los por conta própria, tensionando os próprios saberes com os problemas que se apresentam, desvelando assim seu potencial inventivo.

Com efeito, em jogo, estimula-se um processo autoral. Se está de fato em jogo, se há um engajamento íntegro, o jogador se coloca em situação, em risco. Não memoriza maquinalmente um conteúdo que lhe é estranho, mas reflete, observa e toma ações que o afetam diretamente dentro da realidade lúdica. Nessa perspectiva, o aprendizado não ocorre por meio de informes, depósitos, mas pelo lançamento e solução de problemas investigados na experiência viva da carne dos sujeitos. Pode-se encontrar um eco desse pensamento na afirmação de que a solução de problemas:

[...] elimina a necessidade de o aluno ter que passar pelo professor, e o professor ter que passar pelo aluno para aprender. Ela proporciona a ambos o contato direto com o material, desse modo desenvolvendo o relacionamento ao invés da dependência entre os dois. (SPOLIN, 2018, p. 19).

Tais aproximações ficam ainda mais evidentes ao observar um dos elementos estruturantes do jogo teatral: a avaliação. Nela, os observadores do jogo e seus praticantes, discutem se o problema de atuação foi resolvido e como se deu a resolução. Tal ato não se detém em julgamentos pessoais sobre a performance dos envolvidos, mas sobre critérios objetivos que a prática do jogo evoca. Esse processo é conduzido principalmente por meio de questionamentos vinculados ao foco da atividade, tais como: "o jogador conseguiu materializar a bola?", "ele comunicou em grammelot?", etc. As questões são discutidas pelos participantes e, também, pelo coordenador da atividade que não se exime desta etapa do processo.

A avaliação, ao invés de apontar certezas, propõe questões moventes, estimula os sujeitos a pensar sobre o que fizeram e/ou viram, pro- 
movendo, em certo grau, a curiosidade dos participantes para refletir sobre as respostas destes questionamentos. Nesse processo, a construção de conhecimento ganha uma outra camada. Além da prática na resolução dos problemas do jogo, após sua execução, cria-se um espaço consciente de reflexão e investigação para estranhar e questionar o que o quer que tenha sido executado.

Dessa maneira, o conhecimento aqui produzido não se atém a reprodução de atividades e técnicas, mas incita a investigação sobre o que é realizado e sua decorrente atribuição de sentido. É possível sintetizar o caminho proposto da seguinte maneira: o jogador recebe um problema de atuação, ad-mira este problema e propõe uma solução, após isto, re-ad-mira a própria ad-miração anterior na ad-miração que os parceiros fazem sobre sua performance. Se a primeira ad-miração, a do jogador frente o problema, ocorre de maneira rápida e instantânea, de modo que uma reflexão mais profunda sobre $o$ ato possa ser inibida, a segunda etapa traz a possibilidade de aprofundamento e pode funcionar como disparador da transição de uma curiosidade ingênua para uma curiosidade epistemológica.

Nessa perspectiva, o papel docente na avaliação se torna crucial: é preciso não adotar uma postura bancária que discursa sobe "acertos/erros" e soluções, mas buscar promover a investigação sobre o ocorrido em cena. Caso esta figura consiga se colocar como um educador-educando, pode, inclusive, ressignificar o que já sabe por meio das soluções que seus alunos e alunas deram aos problemas dos jogos e das considerações que realizaram na avaliação. Tem-se então na própria figura docente a acepção do conhecimento como processual, não findado em certezas, mas aberto às transformações oriundas do contato com outros sujeitos.

Com isso, a prática do jogo somada a sua posterior avaliação pode apontar aproximações com o que Freire chamou de pensar certo (FREIRE, 2004a). Para ele, pensar certo é promover um pensamento crítico sobre o apreendido que se afaste de um princípio puramente replicante ou memorizador.
O "intelectual memorizador" sabe muitas informações, mas as repete sem colocá-las em diálogo com a realidade de sua comunidade e seu mundo, reproduz o que fora lido de forma mecânica e dificilmente encoraja um saber pessoal. Na visão de Freire:

A grande tarefa do sujeito que pensa certo não é transferir, depositar, oferecer, doar ao outro, tomado como paciente de seu pensar, a inteligibilidade das coisas, dos fatos, dos conceitos. A tarefa coerente do educador que pensa certo é, exercendo como ser humano a irrecusável prática de inteligir, desafiar o educando com quem se comunica e a quem comunica, produzir sua compreensão do que vem sendo comunicado. (FREIRE, 2004a, p. 38, grifos do autor).

O educador-educando que pensa certo encoraja o educando-educador a questionar o apreendido, a tecer as próprias compreensões sobre o objeto cognoscível. Nessa dinâmica, quando o jogo coloca o sujeito frente a um desafio e, neste processo de avaliação conduzido por questões motivadoras, os praticantes refletem conjuntamente sobre os caminhos traçados, é possível encontrar indícios da promoção deste pensar certo e de um processo de construção de conhecimento. Com isso, a figura do docente evita a ideia de promotor de comunicados para se tornar um problematizador que incita os sujeitos - inclusive ele mesmo - a tecerem suas compreensões sobre o ato.

Contudo, cabe destacar que a proposta freireana do pensar certo está prioritariamente vinculada a questões do universo da comunidade em que os sujeitos estão inseridos, ou seja, aos impactos político-sociais das formas de abordagem do objeto do conhecimento. Apesar de tal fato não ser o objetivo da avaliação indicada por Spolin, posto que a autora orienta que ela se detenha a critérios diretamente vinculados ao foco, isto não enfraquece o potencial questionador e o fomento às compressões pessoais que podem ser geradas no processo.

Vale dizer que mesmo que o processo artístico-pedagógico não aborde diretamente os impactos sociais de uma ação, ele já carrega em sua gênese 
um potencial político ${ }^{4}$. As respostas aos problemas de jogo não estão isentas de interferências culturais e sociais - compete ao educador-educando estar atento se o grupo clama por uma reflexão direcionada aos possíveis ecos político-sociais e, se considerar pertinente, encaminhar a análise para tal lugar.

Por mais que este texto tenha se detido na proposta dos jogos teatrais, defende-se neste manuscrito que proposições de ensino que se aproximam do fundamento lúdico pautado em desafios e que contenham uma etapa de avaliação coletiva podem suscitar o mesmo tipo de processo de construção do conhecimento. Tal afirmativa se faz presente porque muito embora Spolin não oriente seus pensamentos exclusivamente nesta direção, eventualmente suas reflexões são atreladas a uma concepção teatral pautada na estrutura dramática, ponto que, por vezes, não condiz com a dimensão de proposições cênicas existentes hoje. Apesar disso, é possível reconhecer que práticas inspiradas em seu trabalho vêm trazendo cada vez mais propostas que desestabilizam a centralização em torno da narrativa. Tais como as investigações que Ingrid Koudela (2001) fez em estudos posteriores aproximando o jogo teatral da peça didática de Brecht e refletindo sobre a ideia

4 Em artigo publicado anteriormente, defendi que o ensino da arte já carrega um potencial político ao promover certo descondicionamento do olhar, fazendo com que o praticante enxergue o mundo sob óticas que diferem de usos hegemônicos e pré-estabelecidos. Nele, afirmo: "Ao evidenciar modelos totalizantes e desenvolver outras formas de uso e relação com eles, ocorre um certo exercício de alteridade. Não falo da obra artística em si, finalizada, mas de seu processo, o transcorrer de seu desenvolvimento artístico-pedagógico pode estimular um olhar questionador, evidenciar as potencialidades dos sujeitos e das coisas, entendendo que, por mais que um modelo de ação seja o dominante, ele ainda o é, apenas, um dos modelos de ação possíveis. Sob esta ótica, se aponta uma possível fuga do olhar coisificante, pois, assim como as questões e ressignificações que a prática cênica pode propor apontam outras possibilidades de mundo, exercita-se a noção de que este olhar coisificante também é apenas uma possibilidade de se enxergar o mundo e os sujeitos, também é condicionado por um contexto determinado e, por sua vez, passível de ser questionado." (BEZERRA DE SOUZA, 2017, p. 76, 77). de modelo de ação, os estudos de Carmela Soares (2010) que investigam o jogo teatral na sala de aula sob uma ótica performativa, os apontamentos de Maria Lúcia Souza de Barros Pupo (2010) sobre a potência do jogo na abordagem pedagógica de manifestações cênicas contemporâneas, entre outros. Frente a este manancial de possibilidades, a afirmação de Pupo é pertinente ao lembrar que o jogo teatral não é um "sistema acabado". Como ela aponta:

O mérito dessas modalidades se deve ao fato de constituírem princípios de trabalho valiosos, a serem sempre ativados à luz dos contínuos questionamentos que não cessam de transformar as manifestações teatrais em nossos dias. (PUPO, 2005, p. 228).

Acredita-se então que aí se encontra um ponto caro para a aproximação do jogo teatral com a autonomia freireana. Ele é um princípio de ação, não um modelo. Caso seja confundido com um "sistema acabado", "manual de exercícios" ou outra forma de concepção que o encare sob uma perspectiva de mera aplicação, em muito se afastaria da ideia de construção de conhecimento e se aproximaria, na realidade, de uma concepção bancária da educação.

Portanto, para se buscar um processo de ensino-aprendizagem próximo do modo concebido por Freire, há muitos fatores que trespassam o procedimento realizado em sala de aula, incluindo até mesmo a postura da figura docente na realização do ato. Há que se pensar como esse sujeito encara o mundo e seus parceiros no processo de ensino-aprendizagem, se está realmente disposto a se colocar em risco com eles e aprender conjuntamente no desenvolvimento do processo, se abandona a ideia de repetidor de informes e toma para si o desafio de estimular os educandos-educadores a ad-mirar o objeto de estudo, se encoraja o desenvolvimento da curiosidade epistemológica, se está disposto a questionar a própria ad-miração primeva do tema investigado para colocá-la em xeque frente aos outros saberes e vivências agenciadas no processo de ensino-aprendizagem. 


\section{Referências}

BEZERRA DE SOUZA, Henrique. O olhar da Medusa: coisificação e reconfigurações políticas por meio do ensino da arte e prática cênica. Revista Moringa - Artes do espetáculo, João Pessoa, UFPB, v. 8, n. 2, p. 69-80, 2017.

BOAL, Augusto. Teatro do Oprimido e outras poéticas políticas. Rio de Janeiro: Civilização Brasileira, 1980.

CABRAL, Beatriz Ângela Vieira. Drama como método de ensino. São Paulo: Hucitec, 2006.

FREIRE, Paulo. Política e educação. São Paulo: Paz e Terra, 2001.

Pedagogia da Autonomia: saberes necessários à prática educativa. São Paulo: Paz e Terra, 2004a.

Terra, 2004b.

Pedagogia do Oprimido. São Paulo: Paz e

Ação Cultural para liberdade e outros escritos. São Paulo: Paz e Terra, 2018.

HUIZINGA, Johan. Homo Ludens: O jogo como elemento da cultura. Tradução de João Paulo Monteiro. São Paulo: Perspectiva. 2010.

KOUDELA, Ingrid D. Brecht na pós-modernidade. São Paulo: Perspectiva, 2001.

PUPO, Maria Lucia de Souza Barros. Para desembaraçar os fios. Educação e realidade, Porto Alegre, v. 30, n. 2, p. 217-228, 2005.

O Pós-dramático e a pedagogia teatral. In:

GUINSBURG, J.; FERNANDES, Sílvia (Orgs.). O Pós-dramático, p. 221-233. São Paulo: Perspectiva, 2010.
RYNGAERT, Jean-Pierre. Jogar, representar: práticas dramáticas e formação. São Paulo: Cosac Naify, 2009.

SOARES, Carmela. Pedagogia do jogo teatral: uma poética do efêmero: o ensino do teatro na escola pública. São Paulo: Hucitec, 2010.

SPOLIN, Viola. Improvisação para o teatro. Tradução de Ingrid Dormien Koudela e Eduardo José de Alemida Amos. São Paulo: Perspectiva, 2018.

Este é um artigo de acesso aberto distribuído sob os termos de uma Licença Creative Commons Atribuição 4.0 Internacional. Disponível em: http://creativecommons.org/licenses/by/4.0.

This is an open-access article distributed under the terms of the Creative Commons Attribution License 4.0 International. Available at: http://creativecommons.org/licenses/by/4.0.

Ce texte en libre accès est placé sous licence Creative Commons Attribution 4.0 International. Disponible sur: http://creativecommons.org/licenses/by/4.0. 